\title{
Lung Function Test among Abrasive Blasting Workers in Lumut, Perak
}

\author{
Hanis Zakaria ${ }^{1 *}$, Muhammad Faris Fauzy ${ }^{1}$, Mohamad Farid Sies ${ }^{1}$, Mohamad \\ Nur Hidayat Mat $^{1}$, Suhaimi Hassan ${ }^{1}$, Norzelawati Asmuin ${ }^{1}$
}

${ }^{1}$ Faculty of Mechanical and Manufacturing Engineering,

University Tun Hussein Onn Malaysia, Parit Raja, Batu Pahat, 86400, Johor, MALAYSIA

*Corresponding Author: hanisz@uthm.edu.my

DOI: https://doi.org/10.30880/ijie.2019.11.05.017

Received 5 March 2019; Accepted 26 March 2019; Available online 10 August 2019

\begin{abstract}
Abrasive blasting process is a common process in marine industry. This process was use as main cleaning process method and normally will release fine dust that hazardous to human health. Main effect from fine dust to human health are respiratory failure such as chronic obstructive pulmonary disease (COPD). Lung function test can be used to detect any respiratory problems in human. The objective of the research to evaluate the effect of dust exposure from abrasive blasting to the workers. This study is conduct among workers work in dusty environment in Lumut, Perak, Malaysia. $\mathrm{FEV}_{1} / \mathrm{FVC}$ value from lung function test were evaluated to determine the severity of COPD among workers. While $\mathrm{FEV}_{1}$ prediction show restrictive pattern and use to determine any respiratory or lung problems among the workers. From the result, it does not show any COPD problem among workers. However, $\mathrm{FEV}_{1}$ show that some workers need to go for detail medical surveillance because of the result is less than 0.8. Employer and workers need to understand and know their work-related risk to minimize the risk arising from their job or work conducted.
\end{abstract}

Keywords: Lung function test, $\mathrm{FEV}_{1} / \mathrm{FVC}$, FEV prediction, Health Hazard, Abrasive Blasting

\section{Introduction}

The process of abrasive blasting that uses several of abrasive media will release hazardous dusts to workers and people around through inhalation respiration of dust to the lungs. In the year of 2000, Australian Council of Trade Unions (ACTU) conducted the survey concentrated on the chemical in the workplace has found that from 167 respondent, $88 \%$ of respondent said they use the chemicals at work and $33 \%$ said that people at their workplaces have suffered health effect from chemicals at work [1]. Crystalline silica particles can cause both acute and chronic pulmonary inflammatory responses [2-4]. Chronic inhalation studies with crystalline silica in rats have induced pulmonary fibrosis and cancer [5]. In contrast, amorphous silica are regarded as rather innocuous materials that have been reported to cause little or no chronic adverse pulmonary effects [4].

Silicosis is a fibrotic disease of the lungs caused by the inhalation and deposition of free crystalline silicon dioxide $\left(\mathrm{SiO}_{2}\right)$ or silica in the lung tissue [6]. It falls into the group of pneumoconiosis. Silicosis is one of the world's oldest known occupational diseases, characterized by irreversible, progressive lung disease due to the inhalation of crystalline silica [7]. Although the disease is preventable with the proper precautions [8], many individuals are still at risk. Silica exposure has long been a well-known occupational hazard in sandblasting, tunnelling, mining, but also in a range of other professions [9]. Silica can be divided into two basic forms, crystalline and amorphous [7]. Crystalline and amorphous silica have the same molecular formula [10], however the structural arrangements differ [11], crystalline 
silica lattices are regularly arranged while amorphous silica lattices lack order [7]. Fine dust or particulate matter are listed as 5 major or primary air pollutant nowadays [12].

Breathing test or called spirometry test is often done to further evaluate the health of the lungs. Several reference values for spirometry have been published from different parts of the globe, such as pulmonary functions in Europeans, North American populations, and populations from different parts of the Indian subcontinent, Chinese and other nonCaucasian populations [13]. Pulmonary function test or spirometry test are useful for diagnosing the cause of unexplained respiratory systems and monitoring patients or workers with known respiratory disease. Many organizations, including the National Asthma Education and Prevention Program, Global Initiative for Chronic Obstructive Lung Disease (GOLD), and American Thoracic Society (ATS), recommend using these tests [14]. In Malaysia, normally lung disease detect at advance level [15].

In year 2001, blasting sand and five abrasive blasting substitutes were examined as to their ability to induce pulmonary alterations after intratracheal instillation by Hubb et. al. The results of this study indicated that using bronchoalveolar lavage fluid parameters, four of the five substitutes - coal slag, garnet, staurolite, and treated sandproduced pulmonary inflammation and damage equal to or more extensive than that caused by blasting sand, while specular hematite (iron oxide) was significantly less toxic than blasting sand [16]. Then in the year 2002, the study was repeated with different abrasive media; steel grit, copper slag, nickel slag, crushed glass and olivine. Only steel grit produce less effect to rats pulmonary system, but the rest of media give similar effect to pulmonary system as blasting sand does [17]. Both studies show that most dust will be possibly giving health effect to pulmonary system.

Particle size is a main determinant of where in the respiratory tract the particle will come to rest when inhaled [18]. Because of their small size, particles on the order of $\sim 10 \mu \mathrm{m}$ or less (PM10) can penetrate the deepest part of the lungs such as the bronchioles or alveoli [19]. Larger particles are generally filtered in the nose and throat via cilia and mucus, but particles smaller than about $10 \mu \mathrm{m}$, can settle in the bronchi and lungs and cause health problems. Particles which are smaller than $2.5 \mu \mathrm{m}$, tend to penetrate into the gas exchange regions of the lung, and ultra-fine particles $(100 \mathrm{~nm})$ may pass through the lungs to affect other organs, with possible cardiovascular consequences $[17,18]$. The pathogenic effect of dust inhalation on respiratory tissues can be attributed to the direct physical action of dust particles on the epithelium of the human airways and may be exacerbated by the toxic effects of both trace elements (including arsenic, etc.) and of biologically active compounds (bacteria, fungi, pollen, and viruses) [21].

National Asthma Education and Prevention Program, Global Initiative for Chronic Obstructive Lung Disease (GOLD) and American Thoracic Society are recommend pulmonary function test or also well known as lung function test are useful method for diagnosing the cause of unexplained respiratory symptoms and monitoring patients known with respiratory disease [13], [20-22]. An obstructive defect is indicated by a low forced expiratory volume in one second/forced vital capacity $\left(\mathrm{FEV}_{1} / \mathrm{FVC}\right)$ ratio, which is defined as less than lower limit of normal (LLN) in adults, while a restrictive pattern is indicated by an FVC below than LLN in patients [14]. Figure 1 show the step in determine of lung functions test results.

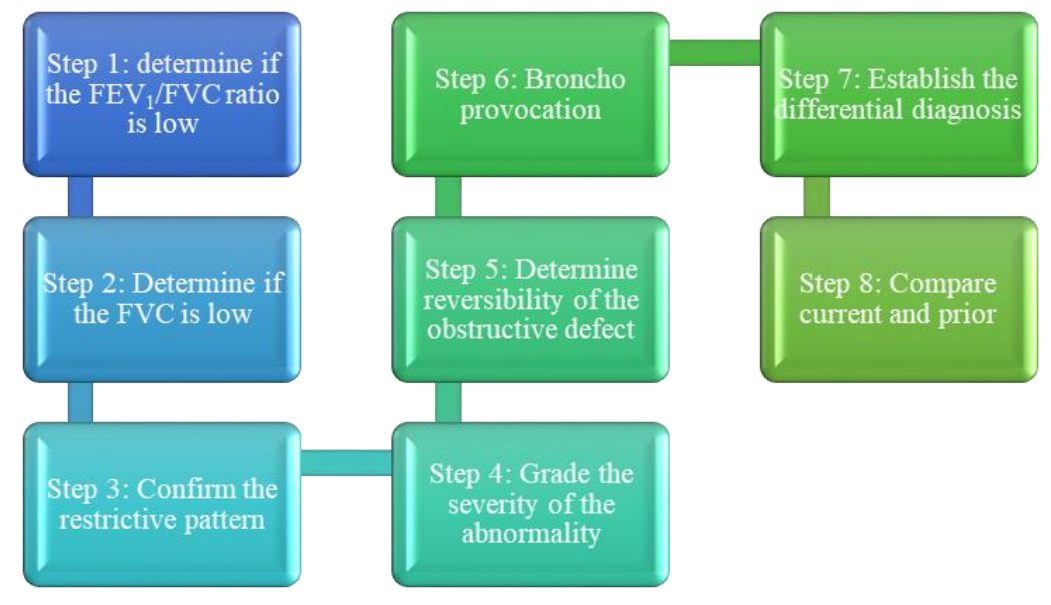

Figure 1: Lung functions test step in determine of problem for patients lung [14].

\section{Methodology}

In this study 18 workers in abrasives blasting environment in marine industry in Lumut, Perak were evaluated. From data, 9 workers are blaster, and 9 workers are non-blaster (engineer, painter, quality control inspector). This company do ship maintenance as their main business. The plant is located at the seaside in Lumut, Perak, Malaysia area. All the workers are well trained workers with specific skill. 
Pulmonary Function Tests were performed on handheld spirometer (Micro Medical DL, UK) connected to spirometer software (Care Fusion, San Diego) on a notebook computer. Spirometer was calibrated daily and a 3L calibration syringe are used [25]. Interviews were conducted before conducting maneuvers to record demographic data, smoking habit and working experience. The maneuver was explained with the help of short video clip demonstration. Tests were conducted according to forced vital capacity procedure of the American Thoracic Society recommends [26]. Measured parameters were forced vital capacity (FVC), forced expiratory volume in 1 second (FEV 1 ) and $\mathrm{FEV} / \mathrm{FVC}$ ratio (expressed as a percentage of the predicted value unit). The predicted set used in this study was taken from Pneumobile Project, Indonesia [27]. Interpretation and derivation of the value of normal, obstruction and restriction lung function result were done according to the American Thoracic Society (ATS) [26]. Figure 2 and table 1 show the standard that has been use in this study.

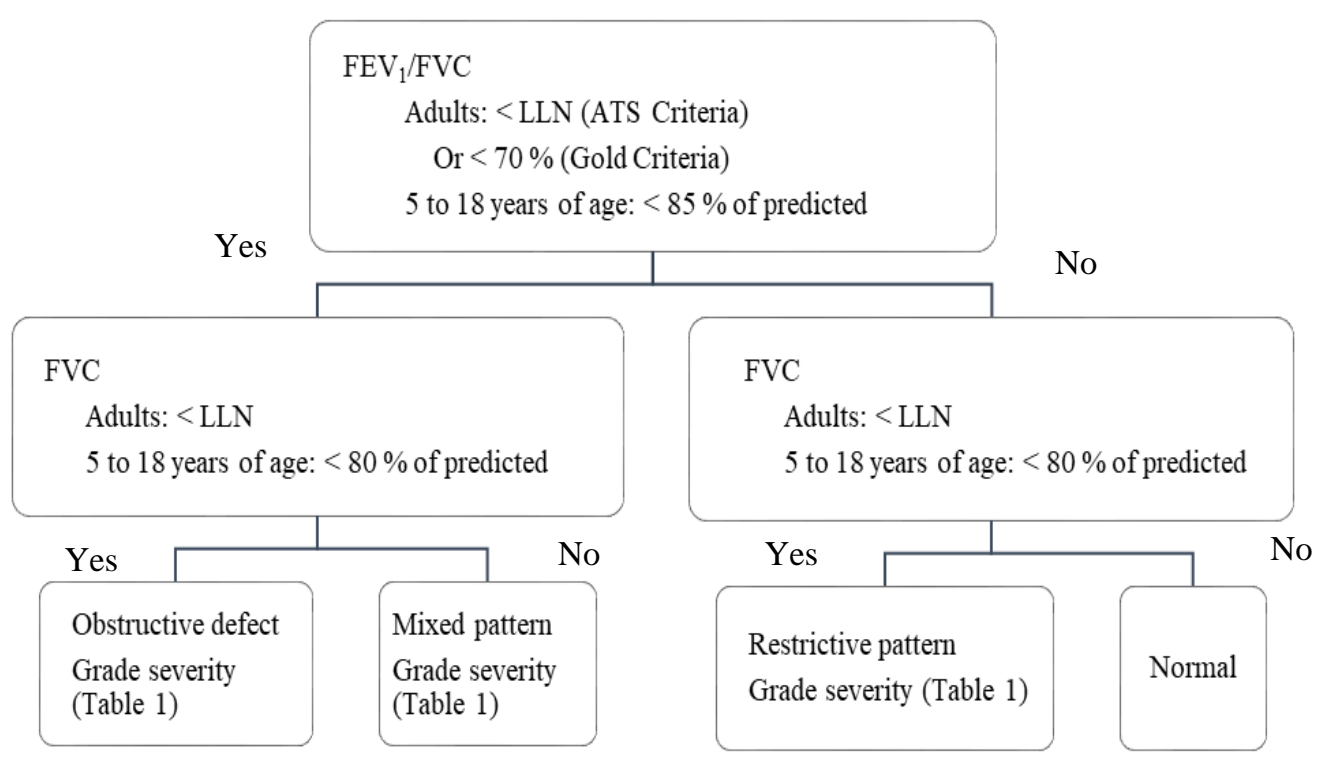

Figure 2 - Interpreting Pulmonary Function Test [14]

Table 1 - American Thoracic Society Grades Severity of Pulmonary Function Test Abnormality [13, 20]

\begin{tabular}{cc}
\hline Severity & $\begin{array}{c}\mathrm{FEV}_{1} \text { percentage of predicted } \\
(\%)\end{array}$ \\
\hline Mild & $>70$ \\
Moderate & 60 to 69 \\
Moderately Severe & 50 to 59 \\
Severe & 35 to 49 \\
Very Severe & $<35$ \\
\hline
\end{tabular}

The environment and standard operating procedure used in the plant also were analyze and observe to get the real information and understand any problem cause by the work system to the workers' health.

\section{Result and Analysis}

From the observation in the plant all the abrasive blasting process were conducted in a closed air system. All abrasive blaster was use full body cover including positive pressure airline system to supply clean air to all blaster. One of the problems during abrasive blasting process was there are no system or equipment were used to suction all the dust release (dust collector) from the abrasive blasting activities. After the abrasives blasting process were done, all the quality control inspector and engineer need to check the abrasive blasting quality. If the blasting process are successfully done all the painter will be come in into close air area to do painting process. All these works need to be done in only 30 to 60 minutes to avoid surface rusting reformation again. Quality inspection workers and painters were only use dust mask as their inhalation protection. For this standard operating procedure will make all the plant' workers expose to the dust equally and maybe quality inspection workers and painter are less protected compare with abrasive blaster. 
Table 2 show the result from lung function test for 18 workers in the abrasive blasting environment. The LLN value for $\mathrm{FEV}_{1} / \mathrm{FVC}$ and FVC were calculated based on Hankinson-1999 [14]. From the table only workers are in normal condition, without having any chronic obstructive pulmonary disease. The worker is just work with the environment for two years and an engineer, not a blaster. This is maybe because the exposure of this worker to the dust environment is still low with limited time. 17 from 18 workers were define have chronic of pulmonary disease with restrictive pattern. According to ATS and Gold criteria, 11 workers are classified mild severity, five workers with moderate severity and one classified as severe. Workers with severe restrictive pattern is a security guard. During assessment and observation during abrasive blasting process have been conduct, this security guard found most of the time is not wear any inhalation protection. Overall, abrasive blasters or any other workers do not show any significance difference in severity of chronic obstructive pulmonary disease pattern. This result show anybody work near to the dust environment have same risk between each other.

Table 2 - Lung Function Test Results and Calculations

\begin{tabular}{|c|c|c|c|c|c|c|c|c|c|}
\hline $\begin{array}{c}\text { Workers } \\
\text { Id }\end{array}$ & $\begin{array}{c}\text { Age } \\
\text { (Years) }\end{array}$ & $\begin{array}{c}\text { Working } \\
\text { Duration } \\
\text { (Years) }\end{array}$ & $\begin{array}{c}\text { Blaster } \\
(\mathbf{Y} / \mathbf{N})\end{array}$ & $\begin{array}{c}\mathrm{FEV}_{1} / \mathrm{FVC} \\
(\%)\end{array}$ & $\begin{array}{c}\text { LLN } \\
\text { FEV }_{1} / \text { FVC } \\
(\%) \\
\end{array}$ & $\begin{array}{c}\text { FEV } \\
\text { Prediction } \\
(\%)\end{array}$ & $\begin{array}{c}\text { FVC } \\
(\mathrm{L})\end{array}$ & $\begin{array}{c}\text { LLN FVC } \\
\text { (L) }\end{array}$ & Smoker \\
\hline 1 & 26 & 2 & Engineer & $92 \%$ & $73.00 \%$ & $102.80 \%$ & 4.29 & 3.81 & $\mathrm{~N}$ \\
\hline 2 & 32 & 4 & $\mathrm{QC}$ & $92 \%$ & $72.20 \%$ & $68.90 \%$ & 2.49 & 3.31 & $\mathrm{~N}$ \\
\hline 3 & 32 & 5 & Engineer & $96 \%$ & $71.80 \%$ & $89.20 \%$ & 4.08 & 4.52 & $Y$ \\
\hline 4 & 29 & 6 & General & $99 \%$ & $72.40 \%$ & $90.10 \%$ & 3.73 & 4.13 & $\mathrm{~N}$ \\
\hline 5 & 34 & 8 & Painter & $83 \%$ & $71.40 \%$ & $70.20 \%$ & 3.62 & 4.43 & $\mathrm{~N}$ \\
\hline 6 & 34 & 11 & $\mathrm{Y}$ & $90 \%$ & $71.40 \%$ & $77.30 \%$ & 3.30 & 3.89 & $Y$ \\
\hline 7 & 39 & 14 & $\mathrm{Y}$ & $90 \%$ & $70.30 \%$ & $81.00 \%$ & 2.68 & 2.95 & $\mathrm{Y}$ \\
\hline 8 & 56 & 15 & Security & $90 \%$ & $66.80 \%$ & $45.90 \%$ & 1.51 & 3.12 & $\mathrm{~N}$ \\
\hline 9 & 43 & 17 & QC & $89 \%$ & $69.50 \%$ & $73.20 \%$ & 2.94 & 3.71 & $Y$ \\
\hline 10 & 41 & 17 & $\mathrm{Y}$ & $81 \%$ & $69.90 \%$ & $64.20 \%$ & 3.22 & 4.24 & $\mathrm{Y}$ \\
\hline 11 & 40 & 18 & General & $90 \%$ & $70.10 \%$ & $89.60 \%$ & 4.03 & 4.21 & $Y$ \\
\hline 12 & 40 & 18 & $\mathrm{Y}$ & $93 \%$ & $70.10 \%$ & $61.60 \%$ & 2.49 & 3.99 & $Y$ \\
\hline 13 & 49 & 18 & $Y$ & $83 \%$ & $68.30 \%$ & $71.90 \%$ & 3.26 & 3.94 & $Y$ \\
\hline 14 & 46 & 20 & Painter & $93 \%$ & $68.90 \%$ & $74.00 \%$ & 2.90 & 3.80 & $Y$ \\
\hline 15 & 46 & 20 & $\mathrm{Y}$ & $98 \%$ & $68.90 \%$ & $67.70 \%$ & 2.53 & 3.80 & $Y$ \\
\hline 16 & 50 & 25 & $\mathrm{Y}$ & $93 \%$ & $68.10 \%$ & $86.30 \%$ & 3.23 & 3.65 & $\mathrm{Y}$ \\
\hline 17 & 57 & 30 & $Y$ & $99 \%$ & $66.60 \%$ & $74.00 \%$ & 2.47 & 3.51 & Y \\
\hline 18 & 56 & 34 & $\mathrm{Y}$ & $94 \%$ & $66.80 \%$ & $66.60 \%$ & 1.86 & 2.72 & $\mathrm{Y}$ \\
\hline
\end{tabular}

Figure 3 show the comparison average value for lung function status result between blaster and non-blaster. For both category of workers, it shows that all of them were recorded have $\mathrm{FEV}_{1} / \mathrm{FVC}$ value greater LLN. Comparing with both work category, it shows that the value for blaster is slightly low compare with non-blaster. For FVC value, both blaster and non-blaster show significance value, below than 0.8 , which non-blaster average value equal to 0.75 and blaster average value 0.67. Referring to Johnson and et. al (2014) all of this worker should go for detail lung function check-up although they are not COPD sufferers [14]. Restrictive pattern show that the lung and pulmonary condition are not in good condition. For all these workers, the effect of dust exposure may result to the restrictive pattern. However, detail investigation still needs to be done before the conclusion for the cause of the problem of status for lung or pulmonary can be made.

Figure 4 is a comparison lung function status between smoker and non-smoker workers. For smoker' workers, most of them have been smoke more than 10 years and their age is around 32 years old to 57 years old. While for nonsmoker' workers, their age in between 26 to 56 years old. Base on this study, the $\mathrm{FEV}_{1} / \mathrm{FVC}$ and FVC value for their lungs do not show any significance difference. The value for $\mathrm{FEV}_{1} / \mathrm{FVC}$ are same for both smoker and non-smoker while, the value of FVC show that, smoker has less 0.03 from non-smoker value. Both groups averagely are in restrictive pattern and in group mild severity. In this study, all blaster are smoker. It's hard to conclude whether the restrictive pattern is cause by the workers' health history (smoker) or because of exposure to the dust. However, all the possibility that might be effect to the lung function are cannot simply avoidable. 


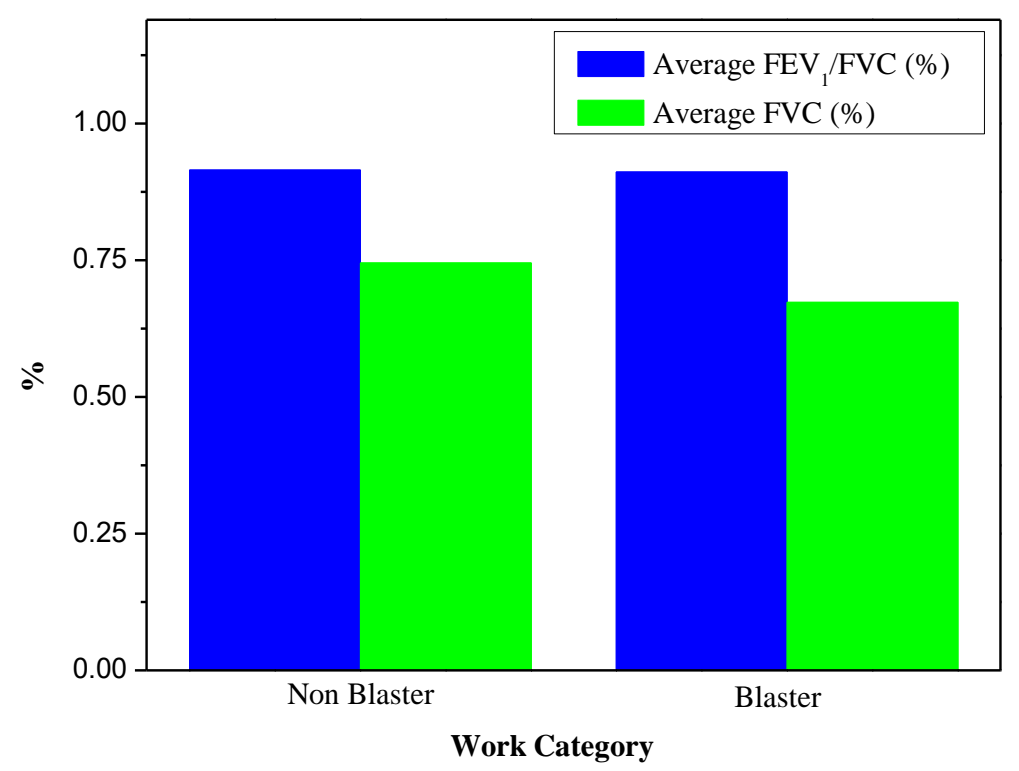

Figure 3 - Average lung function status between blaster and non-blaster

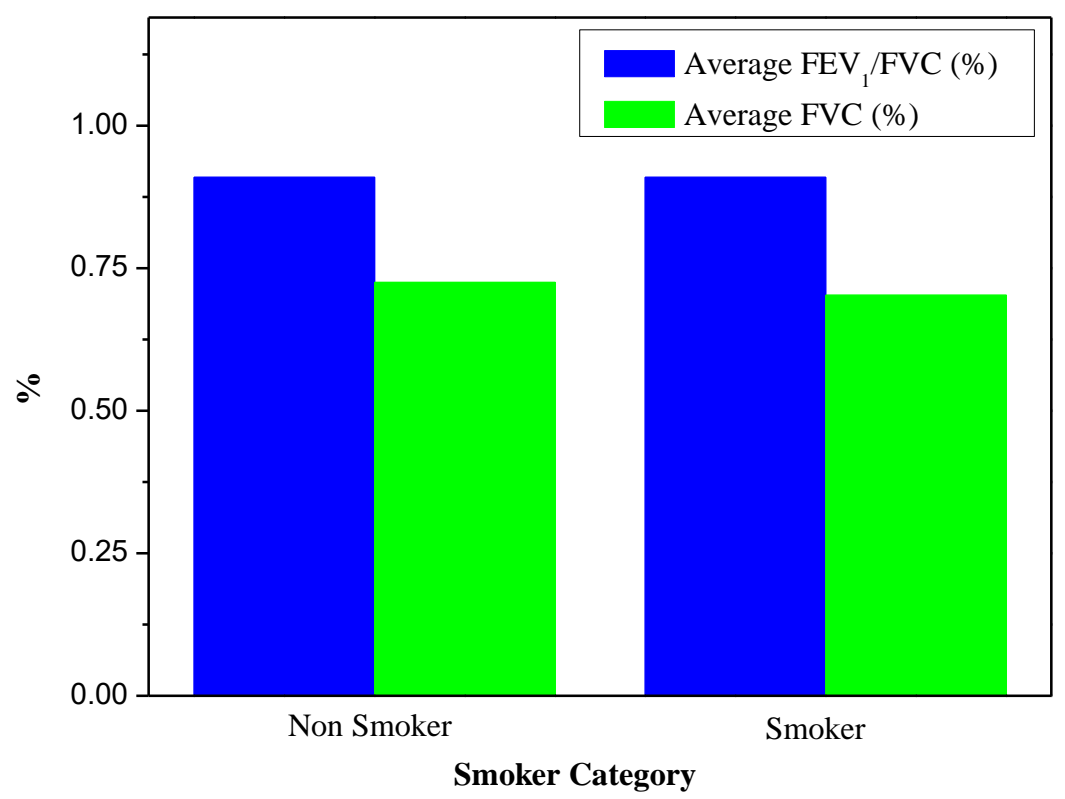

Figure 4 - Comparison lung function status between smokers and non-smoker workers

We can see the changes in lung function performance according their duration of working in the similar environment in figure 5. From the graph we there is no changes for $\mathrm{FEV}_{1} / \mathrm{FVC}$ proportional to their duration of working in the similar environment. Similar environment in these cases mean workers work in abrasive blasting process for marine industries. From the study it's hard to conclude that the dusty environment will increase the possibility if obstructive pulmonary disease among the workers. But from the FVC value, it shows that workers lung may become worse when the duration working in dusty environment are increase. 


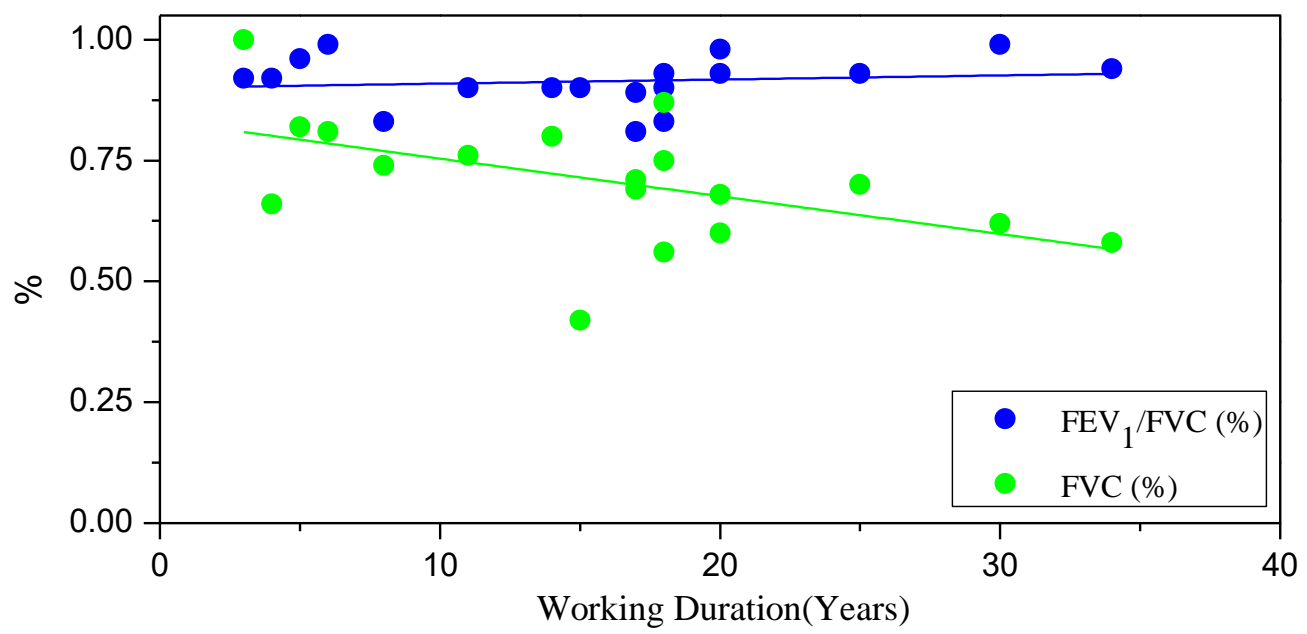

Figure 5 - Lung function status according duration of working in the similar environment.

However, forced expiratory volume in 1 second $\left(\mathrm{FEV}_{1}\right)$ prediction for some workers show that some workers have the reading value lower than 0.70 . According to Johnson \& Theurer, if $\mathrm{FEV}_{1}$ result are less than $70 \%$ it show that full pulmonary function tests with diffusing capacity of the lung for carbon monoxide testing should be ordered to confirm restrictive lung disease and form a differential diagnosis [14].

\section{Summary}

From the result obtain from this study most of workers in the same environment are suffering restrictive pattern of pulmonary disease. Only a worker is categorized as a normal pulmonary function. This situation shows that the duration of working in the abrasive blasting environment may result of problem in pulmonary function. The environment of any task should be taken as the element to evaluate of the risk and hazard to the workers not only their task and job description. For this study it's strongly suggests to all the workers to wear complete inhalation PPE with suitable air protection factor (APF) with the very risk and hazardous environment. Medical surveillance with appropriate and suitable test according to the Occupational Safety and Health regulations should be conduct to monitor and evaluate the health of all the workers in the environment. In this specific case, use of engineering control such as dust collector in the abrasive blasting process will be minimize the risk of exposure of workers to dust release from the process and help prevent any health effect to the workers. Organisational control or management control should be revise to minimize of eliminate the health risk to the workers or people surrounding.

\section{Acknowledgement}

The authors would like to thank the Universiti Tun Hussein Onn Malaysia for supporting this research activity and the publication.

\section{References}

[1] C. Winder, R. Azzi, and D. Wagner, "The Development of the Globally Harmonized System (GHS) of Classification and Labelling of Hazardous Chemicals," J. Hazard. Mater., vol. 125, no. 1-3, pp. 29-44, 2005.

[2] A. Morgan and S. R. Moores, "The Effect of Quartz , Administered by lntratracheal on the Rat Lung . I . The Cellular Response," vol. 12, 1980.

[3] D. H. Bowden and I. Y. R. Adamson, "The role of cell injury and the continuing inflammatory response in the generation of silicotic pulmonary fibrosis," J. Pathol., vol. 144, no. 3, pp. 149-161, 1984.

[4] C. J. Johnston, "Pulmonary Chemokine and Mutagenic Responses in Rats after Subchronic Inhalation of Amorphous and Crystalline Silica," Toxicol. Sci., vol. 56, no. 2, pp. 405-413, 2000.

[5] International Agency for Research on Cancer., "Silica, Some Silicates, Coal Dust and Para-Aramid Fibrils," Lyon, France, 1997.

[6] C. C. Leung, I. T. S. Yu, and W. Chen, "Silicosis,” Lancet, vol. 379, no. 9830, pp. 2008-2018, 2012.

[7] L. M. Costantini, R. M. Gilberti, and D. A. Knecht, "The phagocytosis and toxicity of amorphous silica," PLoS One, vol. 6, no. 2, 2011.

[8] G. Silver, "Editorial: The Inexcusable Persistence of Silicosis Comment: Containing State Health Care Expenditures-The Competition vs Regulation Debate," vol. 85, no. 10, 1995. 
[9] B. Hutyrová, P. Smolková, M. Nakládalovaá, T. Tichý, and V. Kolek, "Case of accelerated silicosis in a sandblaster," Ind. Health, vol. 53, no. 2, pp. 178-183, 2015.

[10] J. H. E. Arts, H. Muijser, E. Duistermaat, K. Junker, and C. F. Kuper, "Five-day inhalation toxicity study of three types of synthetic amorphous silicas in Wistar rats and post-exposure evaluations for up to 3 months," Food Chem. Toxicol., vol. 45, no. 10, pp. 1856-1867, 2007.

[11] R. Merget et al., "Health hazards due to the inhalation of amorphous silica," Arch. Toxicol., vol. 75, no. 11, pp. 625-634, 2002.

[12] M. I. J. Ahmad Fauzi Raffe, Siti Nazahiyah Rahmat, Hazrul Abdul Hamid, "The behavior of Particulate Matter (PM10) Concentrations at Industrial Sites in Malaysia,” Int. J. Integr. Eng., vol. 11, no. 2, pp. 214-222, 2019.

[13] A. Bandyopadhyay, "Pulmonary function studies in young healthy Malaysians of Kelantan, Malaysia," Indian J. Med. Res., vol. 134, no. 11, pp. 653-657, 2011.

[14] J. D. Johnson and W. M. Theurer, "A stepwise approach to the interpretation of pulmonary function tests," Am. Fam. Physician, vol. 89, no. 5, pp. 359-366, 2014.

[15] J. T. Chia Ming, N. Mohd Noor, O. Mohd Rijal, R. M. Kassim, and A. Yunus, "Lung Disease Classification using GLCM and Deep Features from Different Deep Learning Architectures with Principal Component Analysis," Int. J. Integr. Eng., vol. 10, no. 7, pp. 76-89, 2018.

[16] A. F. Hubbs et al., "Comparative Pulmonary Toxicity of 6 Abrasive Blasting Agents," Toxicol. Sci., vol. 61, no. 1, pp. 135-143, 2001.

[17] D. W. Porter et al., "Comparative Pulmonary Toxicity of Blasting Sand and Five Substitute Abrasive Blasting Agents," J. Toxicol. Environ. Health, vol. 65, no. 65, pp. 1121-1140, 2002.

[18] T. Sandstrom and B. Forsberg, "Desert dust: An unrecognized source of dangerous air pollution?," Epidemiology, vol. 19, no. 6, pp. 808-809, 2008.

[19] A. S. Goudie, "Desert dust and human health disorders," Environ. Int., vol. 63, pp. 101-113, 2014.

[20] N. Martinelli, O. Olivieri, and D. Girelli, "Air particulate matter and cardiovascular disease: A narrative review," Eur. J. Intern. Med., vol. 24, no. 4, pp. 295-302, 2013.

[21] T. A. Leski, A. P. Malanoski, M. J. Gregory, B. Lin, and D. A. Stenger, "Application of a broad-range resequencing array for detection of pathogens in desert dust samples from Kuwait and Iraq," Appl. Environ. Microbiol., vol. 77, no. 13, pp. 4285-4292, 2011.

[22] R. Pellegrino et al., "Interpretative strategies for lung function tests," Eur. Respir. J., vol. 26, no. 5, pp. 948-968, 2005.

[23] G. Global Initiative for Chronic Obstructive, "Global strategy for the diagnosis, manaegement and prevention of chronic obstructive pulmonary disease 2018 report," 2018.

[24] National Asthma Education and Prevention Program, "Expert Panel Report 3 (EPR-3): Guidelines for the diagnosis and management of asthma - summary report 2007," 2007.

[25] S. Farhana, Z. Bakri, A. Hariri, M. Ismail, and N. I. Kassim, "Evaluation of Respiratory Symptoms, Spirometric Lung Patterns and Metal Fume Concentrations among Welders in Indoor Air-Conditioned Building at Malaysia," Int. J. Integr. Eng., vol. 10, no. 5, pp. 109-121, 2018.

[26] M. R. Miller et al., "Standardisation of spirometry," Eur. Respir. J., vol. 26, no. 2, pp. 319-338, 2005.

[27] A. Hariri, M. Z. M. Yusof, N. A. Paiman, and A. M. Leman, "Lung Functions of Welders in Three Automotive Related Industries in Malaysia,” J. Ind. Intell. Inf., vol. 3, no. 1, pp. 15-19, 2015. 